Article

\title{
An In-Situ Reference Electrode Insertion Method for Commercial 18650-Type Cells
}

\author{
Limhi Somerville ${ }^{1}$, Stefania Ferrari ${ }^{2, *}$, Michael J. Lain ${ }^{1}$, Andrew McGordon ${ }^{1}$, Paul Jennings ${ }^{1}$ \\ and Rohit Bhagat ${ }^{1}$ \\ 1 WMG, University of Warwick, Coventry CV4 7AL, UK; 1.somerville@warwick.ac.uk (L.S.); \\ m.j.lain@warwick.ac.uk (M.J.L.); A.McGordon@warwick.ac.uk (A.M.); Paul.Jennings@warwick.ac.uk (P.J.); \\ R.Bhagat@warwick.ac.uk (R.B.) \\ 2 Department of Chemistry, Xi'an Jiaotong-Liverpool University (XJTLU), Suzhou 215123, China \\ * Correspondence: stefania.ferrari@xjtlu.edu.cn; Tel.: +86-0512-8188-4966
}

Received: 27 February 2018; Accepted: 3 April 2018; Published: 5 April 2018

\begin{abstract}
This work introduces a new method for inserting a Lithium reference electrode into commercially available 18650-type cells in order to obtain electrode potentials during cell operation. The proposed method is simple and requires limited equipment. Furthermore, electrical performance is significantly better and the cell capacity and resistance can be recorded for longer durations when compared to some of the previously used methods. Electrical performance of this new third electrode method is characterized and compared to 18650 cells with no reference electrode inserted. The capacity retention of the modified cell is more than $98 \%$ in the first 20 cycles. Harvested electrodes from a disassembled cell were also used to make coin cells that was proven to be a rather critical approach to get electrode potentials and capacities. This is an initial study that shows three-electrode performances of a commercial 18650-type cell, which suggests it could be used for understanding electrode behavior throughout a cell lifetime and for manufacturing instrumented cells.
\end{abstract}

Keywords: three-electrode; lithium-ion; electrode potential; aging

\section{Introduction}

Most hand-held and portable electronics use lithium-ion technology to provide off-the-grid power [1]. It is also increasingly being used to facilitate the electrification of automotive vehicles [2,3]. This presents new and unique problems due to the much larger lifetimes ( $8+$ years) automotive batteries require [4].

Over the cells' lifetime, parasitic reactions that are not required for storing or providing energy cause reductions in capacity and power [5]. One way to reduce these reactions and increase cell lifetime is to tightly control the operating conditions (e.g., temperature, the state of charge, and electrical current rate) of the cells [6]. However, to determine the optimal operating conditions, it is helpful to know and understand the reactions that are occurring within the cell and at which electrode [7]. It is possible to track some of these reactions by knowing the individual electrode potentials during the cell cycling [8].

The voltage of the cell is the potential difference between the two electrodes. These are referred to as the working electrode (WE) and the counter electrode (CE). It is not possible to determine the specific potential of a single electrode without the presence of a third reference electrode (RE) [9].

To determine the individual electrode potentials, McTurk et al. [10] inserted either a piece of Li metal foil or Li-plated copper wire as RE into a commercial lithium-ion pouch cell and cycled for 20 cycles. However, as they note, a significant problem with RE insertion is the additional degradation that it can cause. The key areas that McTurk et al. noted as causes of damage were the process of opening the cell, the unknown electrolyte composition of the cell, and the subsequent replacement 
with different materials as well as the impact of resealing it. Their method was a first of its type for applicability to commercial pouch cells.

Due to low costs of manufacturing, high availability, a standardized format across manufacturers, and repeatable electricalperformance, cylindrical 18650-type cells are often utilized for automotive applications.

Determining electrode potentials and electrode reactions from 18650-type cells has been achieved by disassembling the cell and creating two new low capacity half cells with one from each electrode [11]. This is done by cutting electrodes from the original cell, removing active material from one side, washing, and then replacing the electrolyte in a new cell configuration with a RE $[12,13]$. There are numerous problems with this method. Figure 1 contains photographs of two electrodes from commercially available 18650-type cells. It shows that both electrodes are heavily delaminated during the opening and un-rolling process, which makes it difficult to cut out new electrodes that have an equal loading of active material.

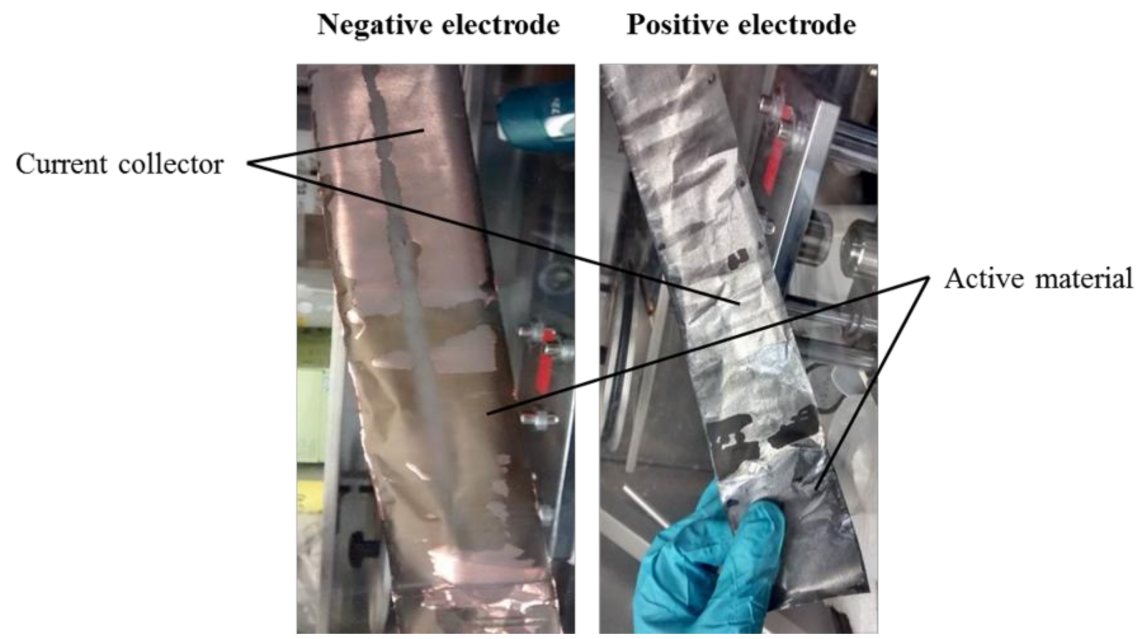

Figure 1. Electrodes removed from a commercially available 18650 cell.

In addition, coin cells created from commercial 18650-type cells require cleaning of one side of the electrode to make a conduction path between the current collector and the cell casing. This cleaning is quite aggressive and can cause further active material loss of the un-cleaned side due to friction. While removing the unwanted side, the liquid solvents used can also react with the electrode on the other side by removing it [14]. Previous work has shown that electrode washing can remove or significantly change the negative electrode surface film [15]. This mixture of cell opening and sample preparation effects led to a quick degradation of the cells. Therefore, the potentials recorded were not likely to be representative of actual cell usage electrode potentials. Furthermore, clearly significant differences exist between the 18650-type cell and coin cells including geometry. A question is being raised about how the results from the two different types of cells can be reliably compared.

In addition to coin cell methods, there are a few examples on a laboratory scale of in-situ three-electrode setups for commercial 18650-type cells. One method used specialized drilling machines to cut a hole in the bottom of the cell can. Due to the production of metal shavings in the cutting process, they also used a magnetic drill bit. The Li reference electrode was then inserted through this hole into an ampoule filled with electrolytes. This approach could not be re-sealed and the cycling had to be performed inside the glove box [16]. A different method was used by Liu et al. in which the bottom of the cell can was removed and submerged in a bath of 1:1, Ethylene Carbonate:Dimethyl Carbonate (EC:DMC) electrolyte and then closed at the top with a stopper [17]. This method is similar to the work of Nagasubramanian who cut both ends off of the cell with a Dremel tool and inserted a Li reference electrode into the mandrel hole. This cell was then kept in a plastic beaker, immersed 
in electrolytes, and cycled within an inert atmosphere [18]. Other iterations such as the Zhang et al. experiment involved the creation of a much larger multi-component cylindrical unit, which could contain the whole cell. An electrolyte was then poured into one end of the unit assembly. This method allowed the cell to be removed from the glove box [19]. The addition of different electrolytes as well as intrusive methods used to gain access negatively impacted the performance. All of these methods are complicated, involve significant machinery, and cause a sharp reduction in cell performance after RE insertion. This is because these methods are primarily meant to measure the electrode potentials. They show little or no information on whether the potentials recorded were representative of real-world values or what effect inserting the reference electrode has on the internal chemistry of the cell. It is possible that, due to changes in the fundamental materials during insertion, the individual electrode performance after electrode insertion is different. This is especially true seeing that the RE cells formed using these other methods did not last longer than a couple of cycles and the difference in electrical performance between these cycles was often significant.

In this paper we introduce a new method for creating three-electrode cylindrical cells by opening commercial 18650-type cells, inserting a Lithium reference electrode, and resealing for use in atmospheric conditions. This method is simple, can be performed at a lower cost, has better performance than half cells or other methods among studies, and enables the cells to be tested in different environments that are more representative of real-world conditions. The effect of this process is measured through electrical characterization by comparing the three-electrode cell with itself before and after RE insertion as well as with fresh cells. Coin cells were also prepared by using electrodes from a dismantled 18650 cell to report about the practicability and effectiveness of this approach. In addition, the material of the three-electrode cell is studied after cycling to determine the impact of the reference electrode insertion process.

\section{Materials and Methods}

\subsection{Cells}

Commercially available, 18650-type cells (ICR18650-26F, Samsung, Seoul, Korea) were purchased. They had a nominal capacity of 2.6 Ah and voltage of 3.7 V. They had a graphite negative electrode and a Nickel Manganese Cobalt (NMC) positive electrode of unknown precise composition. The chemical formulation of the electrolyte was unknown. Prior to RE insertion, cells were discharged to $2.75 \mathrm{~V}$.

\subsection{Coin Cells Production}

A fresh cell was cycled at a low current $(0.4 \mathrm{C}$ rate) for a few cycles, then discharged at $2.75 \mathrm{~V}$, and finally disassembled to make coin cells. It was opened in an Ar-filled glove box $\left(\mathrm{O}_{2}\right.$ and $\left.\mathrm{H}_{2} \mathrm{O}<1 \mathrm{ppm}\right)$ and the electrodes separated. The electrodes were cut using a precision punch and then rinsed in Dimethyl Carbonate (DMC). One of the two sides was removed with N-methyl-2-pyrrolidone to obtain an electrode with a single-coated side. The electrodes were then placed into a vacuum overnight. The calculated areal capacity of the positive electrode was $3.7 \mathrm{mAh} \cdot \mathrm{cm}^{-2}$.

Two electrode half cells were fabricated in 2032 coin cell hardware from Hohsen. Celgard 2325 (Celgard, LLC, Concord, NC, USA) was used as the separator (19 mm diameter) and metal Li as the counter electrode. Fifty $\mu \mathrm{L}$ of electrolyte was then added and were comprised of $1 \mathrm{M} \mathrm{LiPF}_{6}$ in Ethylene Carbonate/Ethyl Methyl Carbonate (EC/EMC) 3:7 v/v and 1 wt \% VC (PuriEl, Soulbrain, Northville, MI, USA). One $0.5 \mathrm{~mm}$ thick spacer and a wave spring were used to maintain electrical contact between the components.

\subsection{RE Insertion}

The insertion was conducted in a glove box under Argon atmosphere $\left(\mathrm{O}_{2}\right.$ and $\left.\mathrm{H}_{2} \mathrm{O}<1 \mathrm{ppm}\right)$. First the cell was pre-tabbed with stainless steel tabs in preparation for cell electrical testing because this is more difficult to do afterward (see Figure 2a). A pipe cutter was then used to cut between the top cap 
and the steel can (see Figure 2b). The Lithium reference electrode was prepared by wrapping lithium metal around a copper wire current collector (diameter $200 \mu \mathrm{m}$ ) and following the procedure reported in Reference [9]. This was then electrically insulated with insulation tape to stop the reference electrode touching the bottom of the steel can and touching the top third of the other end of the copper wire (see Figure 2c). The mandrel pipe was then removed from the center of the jelly roll. Then $3 \mathrm{~mL}$ of DMC was added in its place to counterbalance possible solvent evaporation after which the RE was inserted (see Figure 2d). High temperature, high pressure, chemically resilient Silcoset 151 manufactured by ACC Silicones was used to seal the top cap to the steel can (see Figure 2e) and the cell was then taken out of the glove box to allow the sealant to set for $24 \mathrm{~h}$. The cell was then wrapped with insulating tape to stop inadvertent short circuits and electrical characterization was performed (see Figure 2f,g).
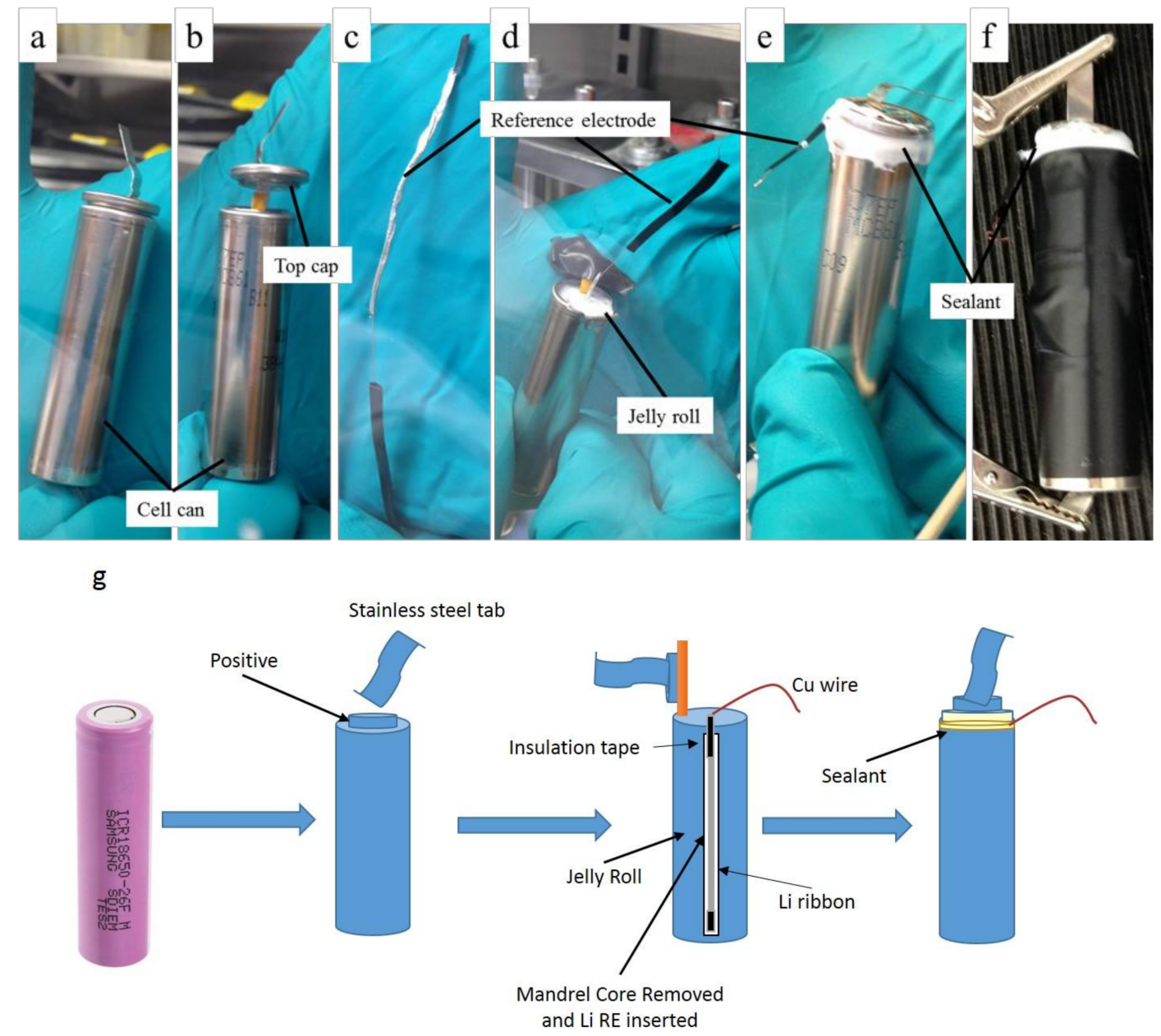

Figure 2. Images taken of a method to open, insert, reseal, and then prepare for electrical characterization of a commercial 18650 lithium-ion cell. (a) The pre-tabbed fresh cell; (b) separated top cap; (c) the RE: Li metal ribbon on Cu wire current collector (black insulation tape at the top and at the bottom); (d) inserting the RE in the mandrel core; (e) resealing the cell; (f) the cell ready for electrical characterization; and $(\mathrm{g})$ the schematic diagram of the method.

\subsection{Electrical Characterization}

According to the manufacturer's specification, the cells were charged at a constant current rate, held at $4.2 \mathrm{~V}$ until the current dropped to $0.005 \%$ of the initial value (constant current/constant voltage cycling; $\mathrm{CC}-\mathrm{CV}$ ), and then discharged to $2.75 \mathrm{~V}$ at a constant current. The first ten cycles were performed at 0.6/0.2 C, the next five cycles were performed at $0.8 / 0.2 \mathrm{C}$, and the final five cycles were performed at $0.8 / 0.4 \mathrm{C}$ for charge/discharge, respectively. Connections to the three electrode 
cells were made using a Biologic VMP3 cycler (Bio-Logic Science Instruments SAS, Seyssinet-Pariset, France). Cell voltage and individual electrode voltages relative to the $\mathrm{Li} / \mathrm{Li}^{+}$reference were recorded as a function of time and capacity using the Biologic VMP3 EC-Lab ${ }^{\circledR}$ software (V10.37, Bio-Logic Science Instruments SAS, Seyssinet-Pariset, France). For cycling, the GCPL6 technique implemented in the Biologic VMP3 EC-Lab ${ }^{\circledR}$ software was used. The cell was kept in a Binder MK climate chamber at $25{ }^{\circ} \mathrm{C}$.

The coin cells were cycled at $25^{\circ} \mathrm{C}$ at $0.05 \mathrm{C}$ rate for fifteen cycles and at $0.2 \mathrm{C}$ for the successive cycles. The cell potentials were kept in the 0.005-2 $\mathrm{V}$ and $2.75-4.2 \mathrm{~V}$ range for the negative and positive electrodes, respectively, by using a Maccor Series 4000 battery cycler (Maccor Inc., Tulsa, OK, USA). The expected nominal capacity for the coin cells was $6.5 \mathrm{mAh}$ and the normalized capacity (\% capacity) was calculated with respect to this value.

\section{Results and Discussion}

Figure 2 shows the six steps used in this research study to instrument an 18650-type cylindrical cell with a Lithium reference electrode. Lithium metal is commonly used as the RE in lithium cells. Early investigations of the behavior of Li metal as RE in carbonates solvents date back to the 1960s [20]. A lithium ribbon electrode compared to electrodeposited $\mathrm{Li}$ and $\mathrm{Li}$ powder was found to be more satisfactory and simple to prepare. Although it has to be considered as a quasi-reference, the potential of a $\mathrm{Li} / \mathrm{Li}^{+}$is reproducible and stable in non-aqueous solutions. Therefore, it is considered appropriate in the study of Li battery technology and is conventionally adopted for this purpose [21].

\subsection{Third Electrode 18650 Results}

Electrical characterization (CC-CV cycling, 20 charge-discharge cycles) was performed on the same cell both before and after RE insertion. These results are shown in Figure 3. Prior to the insertion of the RE, the cell maintained capacity at greater than $99.9 \%$ after each cycle with no discernible capacity fade after 20 cycles. Once the RE was inserted, the capacity of the cell reduced at a greater rate. The reduction in capacity is linear with the cycle number and the capacity retention is still high at above $98 \%$ for the first cycles soon after the insertion of the RE. The overall capacity retention after 20 cycles is $97.5 \%$ for charge and $97.2 \%$ for discharge.

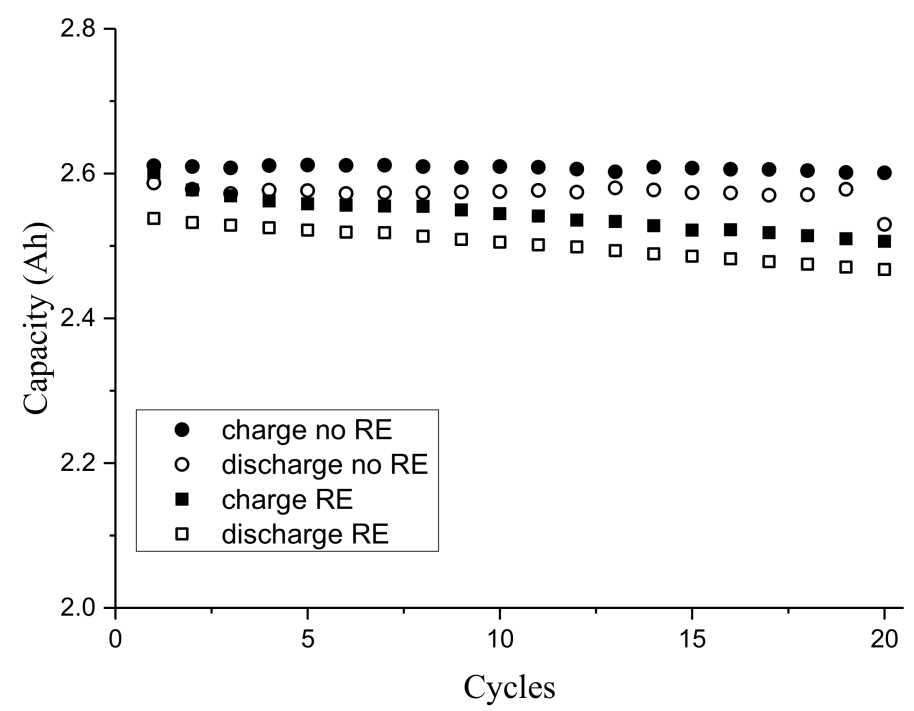

Figure 3. Cycling behavior at $25^{\circ} \mathrm{C}$ of a commercial cell before and after the insertion of a reference electrode (first ten cycles at $0.6 / 0.2 \mathrm{C}$, next five cycles at $0.8 / 0.2 \mathrm{C}$, and the final five cycles at $0.8 / 0.4 \mathrm{C}$ for charge/discharge, respectively). 
Figure 4 shows the voltage behavior of the same cell before and after RE insertion. The voltage profile of the cell after RE insertion shows a slightly higher voltage required for charging, which suggests that the resistance of the cell has increased. This is also shown by the sharper reduction in cell voltage initially during discharge, and also reduced voltage at $1.5 \mathrm{Ah}$ and below during discharge. However, the cell with the RE maintained reasonable agreement with the overall charge/discharge values as the same cell without RE insertion. Although insertion of the RE did increase the resistance of the cell initially, over the course of twenty cycles the resistance does not continue to rise significantly, which suggests it stabilizes after RE insertion.

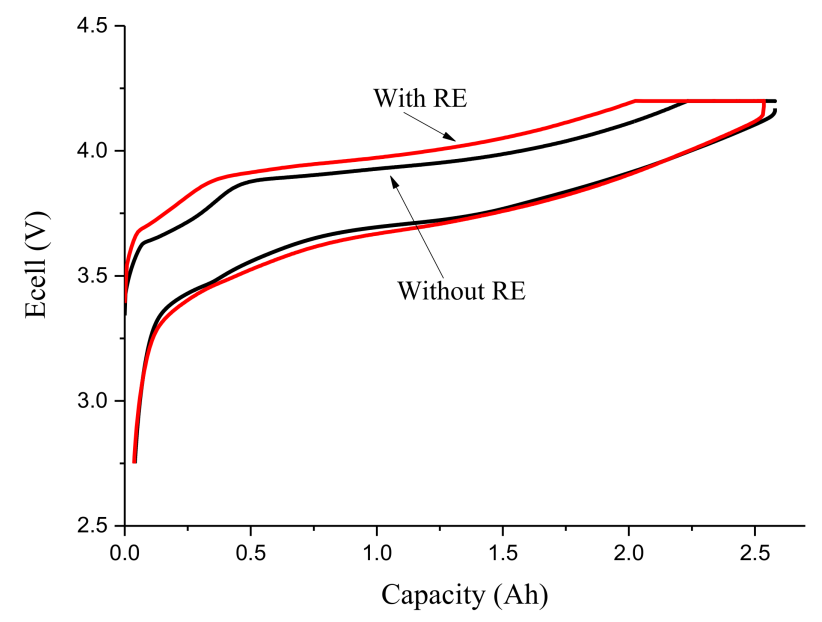

Figure 4. Cell voltage vs. capacity during multiple charge/discharge cycles for the same cell with (red curve) and without (black curve) the RE inserted.

In Figure S1 (Supplementary Materials), the voltage profile of a second cell with the Li reference electrode is compared to that of an unmodified cell. Both cells were fresh (never cycled) before starting the test. The insertion of the RE did not affect the cell capacity or voltage for the first cycles (2nd reported) since the curves are completely superimposed. The cycling behavior is shown in Figure S2. This demonstrates the reliability and reproducibility of the insertion method. Figure 5 shows the voltage behavior of this modified cell and the positive and negative electrodes when measured against the lithium RE. It can be noticed that the anode operated over a relatively narrow voltage window, which suggests that its capacity was not fully utilized. The larger voltage window in which the cathode oscillated could indicate a higher impedance of the positive electrode.

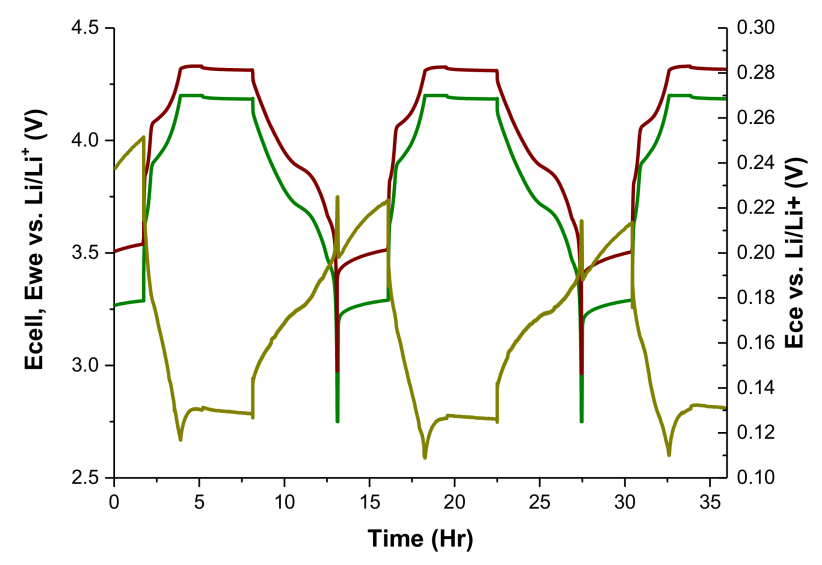

Figure 5. Voltage behavior vs. time of the 18650 cell with RE (green line, left-hand $y$ axis) along with that of the anode (light green line, right-hand $y$ axis) and cathode (brown red line, left-hand $y$ axis). 


\subsection{Coin Cells}

Figure 6 shows the normalized capacity of coin cells compared to the cylindrical cell with the RE inserted over 20 cycles. The normalized capacity was calculated to make the results comparable to those from the modified 18650 . The capacity of both the positive and negative electrodes were far less than expected with the positive electrode at $58 \%$ initially and $92 \%$ at the end while the negative electrode was initially $72.5 \%$ and finally $66 \%$. This shows a reduction of about $6-7 \%$ over 20 cycles. The capacity of the positive electrode coin cell reduced even further when the C-rate increased from $0.05 \mathrm{C}$ to $0.2 \mathrm{C}$. While the positive electrode coin cell maintained capacity sufficiently with each subsequent cycle, the capacity of the negative electrode reduced with each cycle.

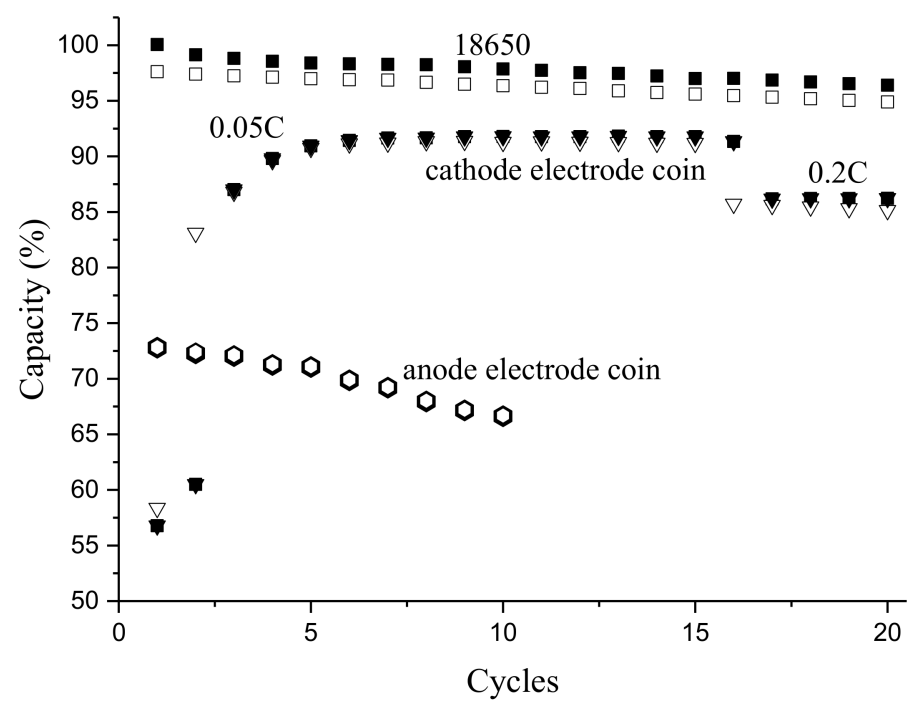

Figure 6. Normalized charge (filled symbols) and discharge (void symbols) capacity vs. the number of cycles for negative electrode (circle) and positive electrode (triangles) half cells from a similar 18650 cell compared to the 18650 cell with RE inserted (squares) vs. capacity during multiple charge/discharge cycles for the same cell.

The 18650-type cell with the RE inserted showed better long-term capacity performance than both of the coin cells. Due to the problems with electrodes used from commercial cylindrical cells (as shown in Figure 1) and the requirement to slowly charge the new coin cells during the initial stages to form new surface films [22], it is evident that the 18650-type RE cell is more suitable for three-electrode studies both initially and over the cell's lifetime.

The potentials of the cathode and anode are compared for both coin cells and the RE inserted cell in Figure 7. Coin cell potentials are compared to 18650 electrode potentials to discuss only the overall trend.

The electrode potentials and capacity in the RE cell underwent small reductions over multiple cycles. In contrast, the coin cells saw significant changes. The graphite electrode capacity reduced by almost $10 \%$. The cathode potential varied a lot during the first five cycles, then stabilizes, but still reduced in each subsequent cycle (particularly when the current rate was increased). This is a problem because, as the positive electrode potential finally stabilizes, the negative electrode undergoes significant capacity losses and chemical change. This makes comparison between potentials and capacity in any subsequent work impossible without assuming that initial positive electrode potential within a larger format 18650-type cell is in-line with negative electrode values after five cycles. The greatest factor is the electrode potential difference between the 18650-type cylindrical cell and the coin cells. The staging of the graphite electrode is observed upon lithiation/delithiation for the negative electrode half-cell while the CE profile of the 18650-type cell did not show any of the same plateaus. The 
negative electrode coin cell was cycled at a lower current rate than the cylindrical cell and the design of the cells is different, which implies different interfacial resistances. Therefore, total impedance may account for the significant difference in the voltage profile. Because the 18650-type cell electrodes are larger (greater distance from tabs) and wound, it is subject to non-uniform charge distribution during cycling and, as a consequence, it is difficult to discern a voltage profile at medium/high current rates like that seen in small coins where phase transitions/equilibria can be observed.
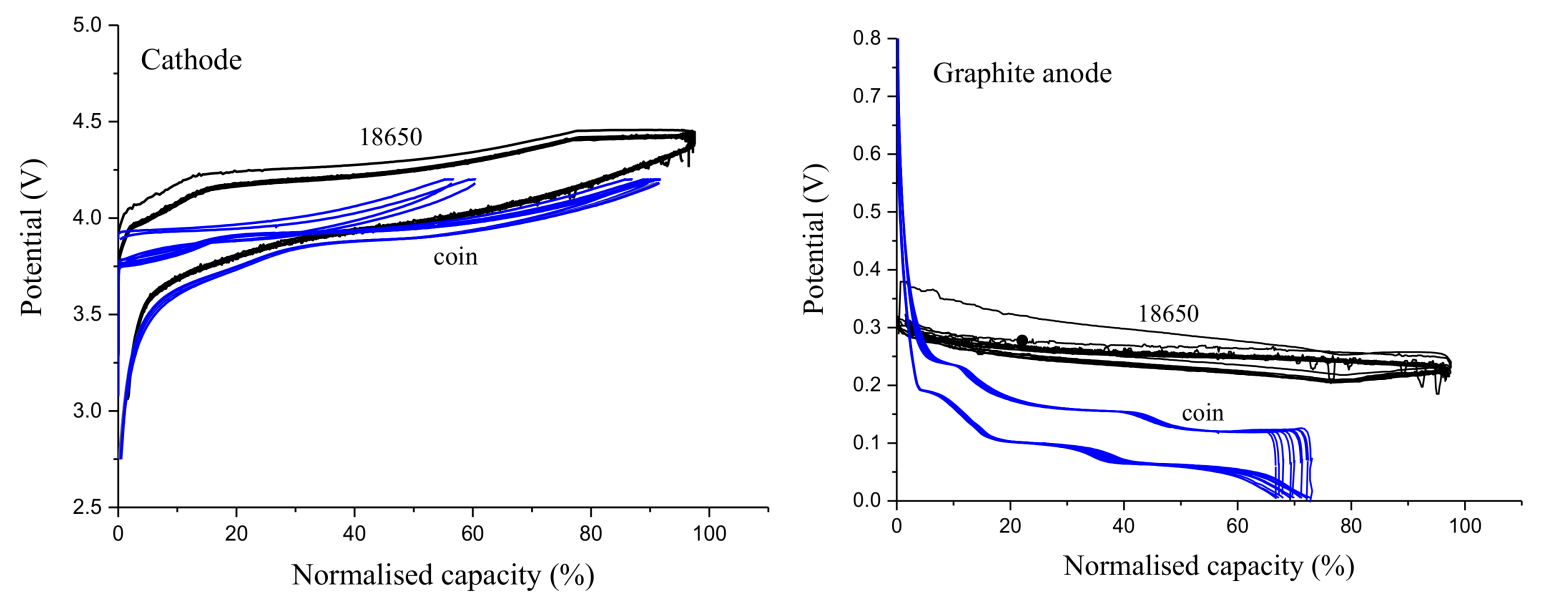

Figure 7. Coin cell potentials (blue curve) for the cathode (on the left) and the graphite anode (on the right) and the three-electrode 18650 cell electrode potentials (black curve) vs. capacity. The first five cycles of the cathode coin cell are those at higher potentials in the middle of the positive electrode coin cell values.

In general, it is well accepted that the mechanism of aging in cylindrical cells is not uniform [13,23-25] due to a mixture of cell design, manufacturing, operating conditions, and other parasitic reactions including an internal temperature rise due to repeated cycling [26]. For these reasons, it is evident that a complete cell has much more practical information than a small sampled piece of an electrode that may not be enough representative of the entire electrode due to localized inhomogeneity, especially when cell degradation is under investigation.

Therefore, what this paper shows is that the creation of coin cells from commercial 18650-type cells leads to a large reduction in capacity at both electrodes and an increase in impedance. In addition, it is not possible to determine whether this impact is uniform for both electrodes. If it is not, then there is no way to determine what the localized impact of capacity fade and increased resistance is at each electrode. Therefore, individual electrode potentials determined within coin cells may not be accurate. Previous studies also revealed higher internal resistance, higher cell voltages, and lower capacities at increasing current rates for reconstructed cells compared to an 18650-type cell [13]. In contrast, the insertion of an RE within an intact 18650 cell maintains more consistent, representative performance and electrode potential values both initially and after multiple cycles.

\subsection{Effect of RE Insertion Procedure on Internal Cell Components}

After electrical characterization and cycling, the RE 18650 cell was re-opened to determine the effect of the reference electrode insertion. Figure 8 contains four images that show the visible impact of our method. The silicon-based sealant had sealed the top cap to the can and was solidified into the top of the jelly roll (see Figure 8a). It had not come into contact with the electrode active material but had remained in the separator. The lithium RE had maintained its lithium metal color and was subsequently successfully used as an RE in another cell (see Figure $8 b$ ). The bottom of the electrode $(<5 \mathrm{~mm})$ furthest from the top cap had changed and is shown in Figure $8 \mathrm{c}, \mathrm{d}$. This is typical of surface film changes as a consequence of adding different electrolyte solvents. The surface film changes 
were present on both the graphite and NMC-based electrodes. Although chemical changes do not always exhibit themselves visually, any visual change in material color or texture is indicative of a chemical change. The electrolyte solvent DMC that was added to the cell to provide a conduction path between the reference electrode and the other electrodes had made chemical changes. If the same electrolyte solvents were used during RE insertion as was found in the cell, it may be possible to limit or reduce cell damage. This is not possible with commercial cells. However, their use is more suitable for consistent electrical performance.
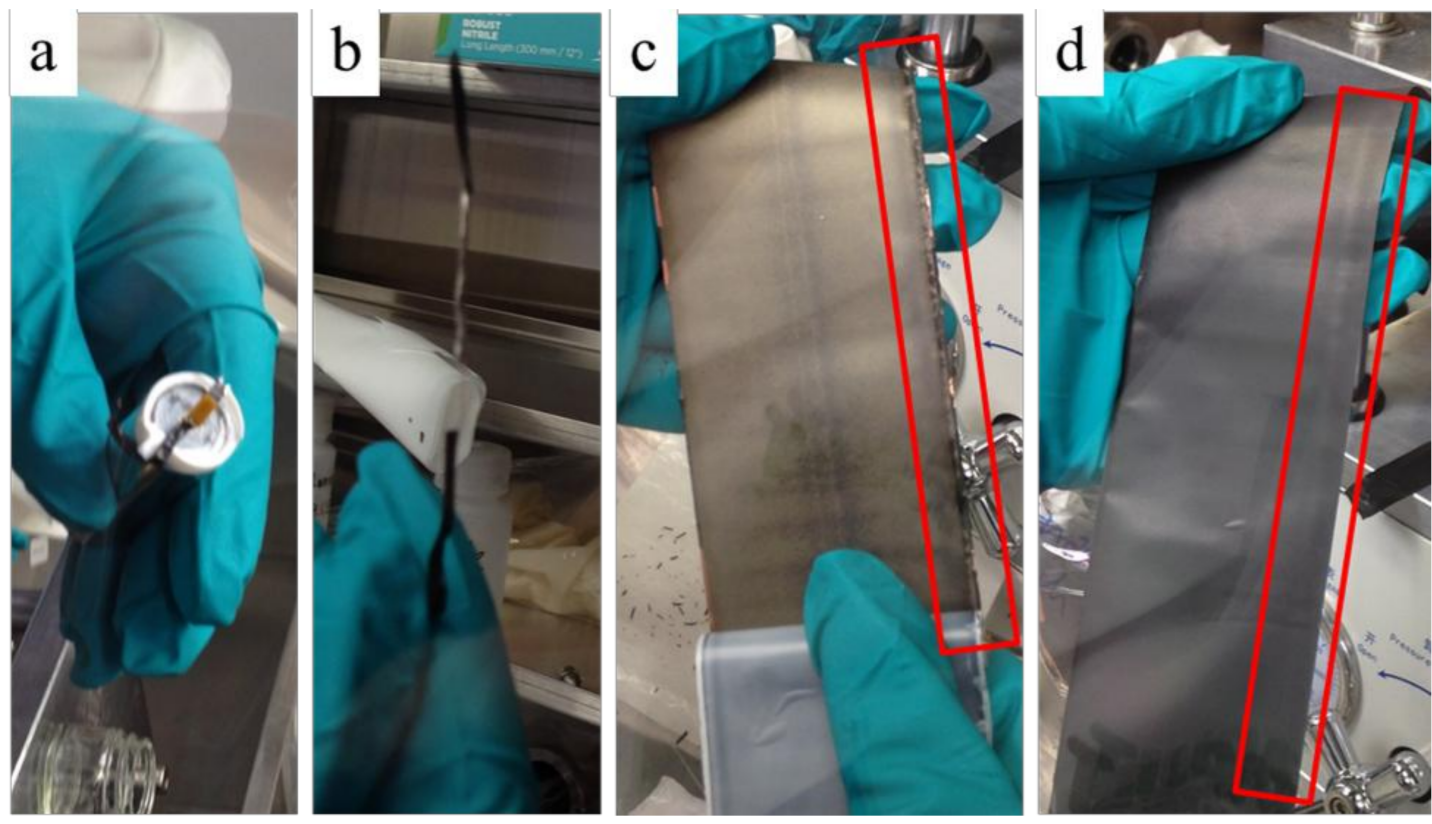

Figure 8. Images taken of the RE cell after electrical characterization and testing. The top of the cell after the cap has been removed as shown in (a), the reference electrode after testing is shown in (b). The red boxes indicate visual changes observed at the negative electrode (c) and the positive electrode (d) is furthest from the cell top cap.

\section{Conclusions}

Information on the specific potentials of electrodes over a cell lifetime is of use in determining the location and type of damage sustained. Coin cell creation from commercial 18650 cells is well-known to be difficult and, in this work, produced inconsistent results that changed over only a few cycles. There are always artifacts associated with cell disassembly. These artifacts are affected by the cell disassembly process and ambient conditions. In any case, electrode potentials during cell operation remain undetermined by examining electrodes extracted from the cell.

The previous methods to insert reference electrodes into 18650-type cells caused significant damage to the electrode materials and led to rapid performance decline, which makes them unrepresentative of real-world conditions.

However, this work presented a reliable method for inserting a reference electrode into a commercial 18650-type cell. The material degraded more slowly and more consistently during cell cycling and allowed for in-situ three-electrode studies over at least 20 cycles. Inserting the Li RE caused little degradation, which was observed visually. This may be overcome by using identical electrolyte solvents during RE insertion as were used during the cell manufacture.

This method is simple, involves less equipment, and produces fairly good electrical results compared to other methods found in past studies including research on coin cells. This approach can be the first step towards developing instrumented lithium-ion batteries embedding commercially available sensors. 
Supplementary Materials: The following are available online at http:/ www.mdpi.com/2313-0105/4/2/18/s1, Figure S1: comparison of cell potential, Figure S2: cycling behavior of a second cell.

Acknowledgments: This research was supported by the Engineering and Physical Science Research Council (EPSRC-EP/I01585X/1). This research was undertaken in collaboration with the WMG Center High Value Manufacturing Catapult (funded by Innovate UK) and Jaguar Land Rover. The authors also acknowledge support from EPSRC under award EP/M009394/1 (ELEVATE, Electrochemical Vehicle Advanced Technology project).

Author Contributions: Stefania Ferrari and Limhi Somerville contributed equally. Stefania Ferrari and Limhi Somerville conceived the experiments. Limhi Somerville performed the cell modification. Stefania Ferrari made the coin cells and performed all electrical characterization. Stefania Ferrari and Michael J. Lain analyzed the data. Andrew McGordon, Paul Jennings, and Rohit Bhagat contributed reagents/materials/analysis tools. Limhi Somerville and Stefania Ferrari wrote the paper. All authors revised the paper.

Conflicts of Interest: The authors declare no conflict of interest.

\section{References}

1. Tarascon, J.-M.; Armand, M. Issues and challenges facing rechargeable lithium batteries. Nature 2001, 414, 359-367. [CrossRef] [PubMed]

2. Panchal, S.; McGrory, J.; Kong, J.; Dincer, I.; Agelin-Chaab, M.; Fraser, R.; Fowler, M. Cycling degradation testing and analysis of a $\mathrm{LiFePO}_{4}$ battery at actual conditions. Int. J. Environ. Res. 2017, 41, 2565-2575. [CrossRef]

3. Panchal, S.; Dincer, I.; Agelin-Chaab, M.; Fraser, R.; Fowler, M. Uneven temperature and voltage distributions due to rapid discharge rates and different boundary conditions for series-connected $\mathrm{LiFePO}_{4}$ batteries. Int. Commun. Heat Mass 2017, 81, 210-217. [CrossRef]

4. Zhang, Y.; Wang, C.-Y.; Tang, X. Cycling degradation of an automotive $\mathrm{LiFePO}_{4}$ lithium-ion battery. J. Power Sources 2011, 196, 1513-1520. [CrossRef]

5. Broussely, M.; Biensan, P.; Bonhomme, F.; Blanchard, P.; Herreyre, S.; Nechev, K.; Staniewicz, R. Main aging mechanisms in Li ion batteries. J. Power Sources 2005, 146, 90-96. [CrossRef]

6. Lu, L.; Han, X.; Li, J.; Hua, J.; Ouyang, M. A review on the key issues for lithium-ion battery management in electric vehicles. J. Power Sources 2013, 226, 272-288. [CrossRef]

7. Blyr, A.; Sigala, C.; Amatucci, G.; Guyomard, D.; Chabre, Y.; Tarascon, J.M. Self-discharge of $\mathrm{LiMn}_{2} \mathrm{O}_{4} / \mathrm{C}$ Li-ion cells in their discharged state understanding by means of three-electrode measurements. J. Electrochem. Soc. 1998, 145, 194-209. [CrossRef]

8. Abraham, D.; Reynolds, E.; Sammann, E.; Jansen, A.; Dees, D. Aging characteristics of high-power lithium-ion cells with $\mathrm{LiNi}_{0.8} \mathrm{Co}_{0.15} \mathrm{Al}_{0.05} \mathrm{O}_{2}$ and $\mathrm{Li}_{4 / 3} \mathrm{Ti}_{5 / 3} \mathrm{O}_{4}$ electrodes. Electrochim. Acta 2005, 51, 502-510. [CrossRef]

9. Ives, D.J.; Janz, G.J.; King, C. Reference electrodes: Theory and practice. J. Electrochem. Soc. 1961, 108, 246C-247C. [CrossRef]

10. McTurk, E.; Birkl, C.; Roberts, M.; Howey, D.; Bruce, P. Minimally invasive insertion of reference electrodes into commercial lithium-ion pouch cells. ECS Electrochem. Lett. 2015, 4, A145-A147. [CrossRef]

11. Aurbach, D.; Markovsky, B.; Talyossef, Y.; Salitra, G.; Kim, H.-J.; Choi, S. Studies of cycling behavior, ageing, and interfacial reactions of $\mathrm{LiNi}_{0.5} \mathrm{Mn}_{1.5} \mathrm{O}_{4}$ and carbon electrodes for lithium-ion 5-V cells. J. Power Sources 2006, 162, 780-789.

12. Abraham, D.; Knuth, J.; Dees, D.; Bloom, I.; Christophersen, J. Performance degradation of high-power lithium-ion cells-Electrochemistry of harvested electrodes. J. Power Sources 2007, 170, 465-475. [CrossRef]

13. Waldmann, T.; Kasper, M.; Wohlfahrt-Mehrens, M. Optimization of charging strategy by prevention of lithium deposition on anodes in high-energy lithium-ion batteries-electrochemical experiments. Electrochim. Acta 2015, 178, 525-532. [CrossRef]

14. Malmgren, S.; Ciosek, K.; Lindblad, R.; Plogmaker, S.; Kühn, J.; Rensmo, H.; Edström, K.; Hahlin, M. Consequences of air exposure on the lithiated graphite SEI. Electrochim. Acta 2013, 105, 83-91. [CrossRef]

15. Somerville, L.; Bareño, J.; Jennings, P.; McGordon, A.; Lyness, C.; Bloom, I. The effect of pre-analysis washing on the surface film of graphite electrodes. Electrochim. Acta 2016, 206, 70-76. [CrossRef]

16. Belt, J.R.; Bernardi, D.M.; Utgikar, V. Development and use of a Lithium-metal reference electrode in aging studies of Lithium-ion batteries. J. Electrochem. Soc. 2014, 161, A1116-A1126. [CrossRef] 
17. Liu, P.; Wang, J.; Hicks-Garner, J.; Sherman, E.; Soukiazian, S.; Verbrugge, M.; Tataria, H.; Musser, J.; Finamore, P. Aging mechanisms of $\mathrm{LiFePO}_{4}$ batteries deduced by electrochemical and structural analyses. J. Electrochem. Soc. 2010, 157, A499-A507. [CrossRef]

18. Nagasubramanian, G. Two-and three-electrode impedance studies on 18650 Li-ion cells. J. Power Sources 2000, 87, 226-229. [CrossRef]

19. Zhang, Y.; Wang, C.-Y. Cycle-life characterization of automotive lithium-ion batteries with $\mathrm{LiNiO}_{2}$ cathode. J. Electrochem. Soc. 2009, 156, A527-A535. [CrossRef]

20. Burrows, B.; Jasinski, R.J. The Li/ $\mathrm{Li}^{+}$reference electrode in propylene carbonate. J. Electrochem. Soc. 1968, 115, 365-367. [CrossRef]

21. Isutzu, K. Reference Electrodes for Use in Nonaqueous Solutions. In Handbook of Reference Electrodes; Inzelt, G., Lewenstam, A., Scholz, F., Eds.; Springer: Berlin, Germany, 2013; pp. 145-187.

22. Aurbach, D.; Markovsky, B.; Weissman, I.; Levi, E.; Ein-Eli, Y. Correlation between surface chemistry and performance of graphite negative electrodes for Li ion batteries. Electrochim. Acta 1999, 45, 67-86. [CrossRef]

23. Illig, J.; Schmidt, J.; Weiss, M.; Weber, A.; Ivers-Tiffée, E. Understanding the impedance spectrum of 18650 $\mathrm{LiFePO}_{4}$-cells. J. Power Sources 2013, 239, 670-679. [CrossRef]

24. Klett, M.; Eriksson, R.; Groot, J.; Svens, P.; Högström, K.C.; Lindström, R.W.; Berg, H.; Gustafson, T.; Lindbergh, G.; Edström, K. Non-uniform aging of cycled commercial $\mathrm{LiFePO}_{4} /$ /graphite cylindrical cells revealed by post-mortem analysis. J. Power Sources 2014, 257, 126-137. [CrossRef]

25. Prezas, P.D.; Somerville, L.; Jennings, P.; McGordon, A.; Basco, J.; Duong, T.; Bloom, I. Effect of Fast Charging of Lithium-Ion Cells: Performance and Post-Test Results; SAE Technical Paper; SAE International: Warrendale, PA, USA, 5 April 2016.

26. Waldmann, T.; Bisle, G.; Hogg, B.-I.; Stumpp, S.; Danzer, M.A.; Kasper, M.; Axmann, P.; Wohlfahrt-Mehrens, M. Influence of cell design on temperatures and temperature gradients in Lithium-ion cells: An in operando study. J. Electrochem. Soc. 2015, 162, A921-A927. [CrossRef]

(C) 2018 by the authors. Licensee MDPI, Basel, Switzerland. This article is an open access article distributed under the terms and conditions of the Creative Commons Attribution (CC BY) license (http:// creativecommons.org/licenses/by/4.0/). 